
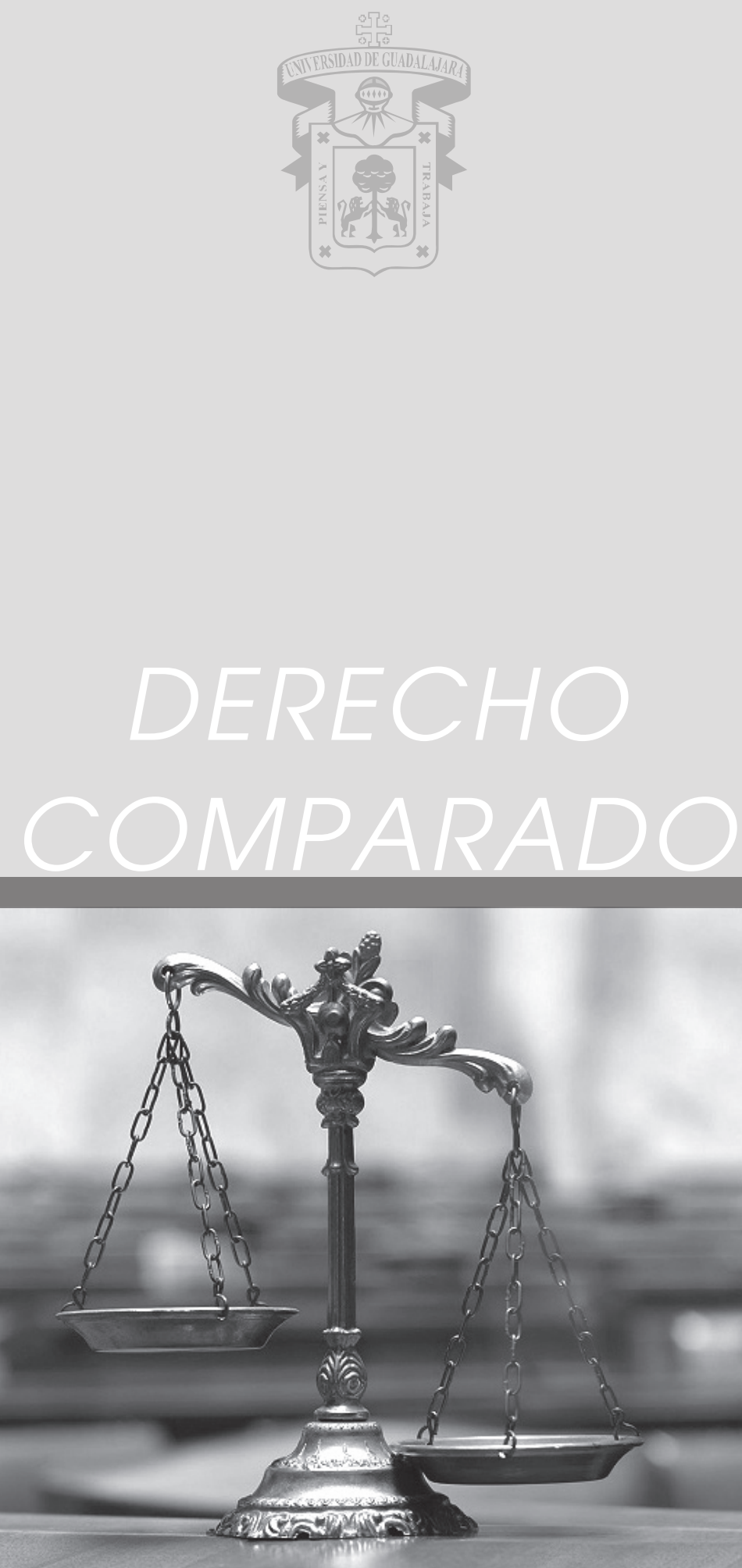


$$
\bar{x}
$$




\section{¿Daño moral a un agresor ilegítimo?}

Mariela Esther Mellace

Fallo comentado: Juzgado Letrado de Salto de $6^{\circ}$ Turno 12-09-2012 C., L. y otros C. P.G., V. D. Cita Online: UY/ JUR/777/2012

SUMARIO: I. Los hechos. II. ¿Estado de necesidad o legítima defensa? Delimitaciones conceptuales de institutos penales en la sentencia civil. III. Conclusiones

\section{Los hechos}

Considero relevante antes de abordar el análisis del presente caso, delimitar de manera circunstanciada cuales fueron los hechos.

El domingo 11 de noviembre de 2007 , alrededor de las 14.00 hs., un sujeto "C" ingresó a un domicilio ajeno sin autorización. El dueño de la morada "P" estaba durmiendo la siesta $y$ al despertar vio a una persona por el pasillo lateral de su casa. Por esta razón, tomó una pistola calibre $9 \mathrm{~mm}$ que tenía sobre un mueble y salió corriendo hacia la puerta lateral que accede al patio de la casa. Allí encontró a "C" con una pierna de cada lado del segundo portón, le gritó que no se moviera pero éste se inclinó hacia él. Al ver esa reacción, "P" efectuó instintivamente un disparo con el arma de fuego causándole a "C" lesiones en la médula espinal que le causó paraplejia.

"C" le inicia una acción de daños y perjuicios a "P" y le reclama los siguientes rubros indemnizatorios: por daño moral a la víctima $\$ 800.000$, a su madre $\$ 400.000$ y a sus hermanos $\$ 100.000$ cada uno, así como también los gastos médicos no cubiertos por la operación, traslados, consultas y medicamentos que se estiman en $\$ 100.000$.

El juzgado resolvió que la reacción para repeler la agresión fue desmedida $y$, como habría existido "concurrencia de culpas", impuso al defensor la carga de indemnizar la mitad de los daños invocados por el intruso y sus familiares.

En su mérito se lo condenó a v. D. P. G. a pagar por concepto de daño moral a L. C. la suma de $\$ 200.000$, a Z. S. la suma de $\$ 75.000$, la suma de $\$ 25.000$ para cada hermano, la suma de $\$$ 
17.500 para cada uno de los hermanos f. Y f. C. Y \$ 12.500 para g. V. C., mas reajustes e intereses legales que correspondan conforme d.I. 14.500.

Asimismo se lo condenó al demandado a pagar a los actores la suma de $\$ 25.000$ por concepto de daño patrimonial por gastos hospitalarios mas reajustes e intereses legales.

\section{II. ¿Estado de necesidad o legítima defensa? Delimitaciones conceptuales de institutos penales en la sentencia civil}

En primer término en el fallo confunden claramente dos causas de justificación distintas: la legítima defensa (art. 34 inc. 6 y 7 CP) y el estado de necesidad justificante (art. 34 inc.3 CP). Así lo sostuvo el tribunal (...) no se verificó uno de los elementos configurativos de la eximente de responsabilidad, concretamente el que refiere a "la racionalidad del medio empleado" que exige el art. 26 del Cdo. Penal. $Y$ este es el elemento que se erige como concepto o punto clave del instituto por cuanto si hay racionalidad se configura la legítima defensa pero si no la hay es claro que la parte no queda exonerada de responsabilidad. (...)La reacción de P. fue claramente desmedida, no guardo la debida proporción ni racionalidad del medio empleado para repeler la agresión.

En conclusión, para que opere la eximente ya sea de la legítima defensa o del estado de necesidad, el mal causado debe ser menor o igual al que se quiere evitar (...) de donde parece razonable concluir que P. actuó en la ocasión en forma desmedida, no hizo un uso racional del medio empleado para repeler el ingreso no autorizado de C. con obviamente fines delictivos.

Ahora bien, recordemos brevemente los conceptos de legítima defensa y de estado de necesidad justificante que operan como causas de justificación y por ende, excluyen la antijuridicidad del comportamiento dañoso. Para ello, tomaremos el concepto de Orgaz que expresa que la defensa privada es legítima cuando en situación de necesidad y con medios racionales, alguien repele de sí o de otro una agresión actual e ilegítima.(1)

Llambías, por su parte, considera que existe legítima defensa cuando alguien frente a una agresión ilegítima y no provocada, 
emplea un medio racional y suficiente para impedirla o repelerla. (2)

Entonces defino a la legítima defensa (art. 34, inc. 6 del CP) como a la conducta efectuada por un sujeto que tiene por finalidad repeler una agresión considerada ilegítima, de acuerdo a su percepción objetiva y/o subjetiva (3), la cual necesariamente tendrá que ser impedida o repelida de manera racional en cuanto al medio empleado, debiendo existir por parte del individuo que se defiende la denominada "falta de provocación" (4). El estado de necesidad justificante, por su parte, está regulado en el art. 34, inc. 3 del CP y establece que no es punible quien causare un mal por evitar otro mayor inminente a que ha sido extraño. Aquí se presentan dos bienes jurídicos de distinta jerarquía, razón por la cual el individuo decide vulnerar el bien jurídico de menor relevancia en pos de salvaguardar uno de rango superior. El daño causado debe ser inferior al que amenaza. Así por ejemplo un sujeto advierte una situación de incendio en una vivienda y, para salvar la vida de una persona que reside allí, vulnera la puerta y la rescata.

Así lo afirma el penalista Rusconi la propia redacción de la eximente pone de manifiesto los requisitos para su funcionamiento: 1. Un conflicto de males. 2. Una diferencia jerárquica entre los dos males en conflicto. 3. La ajenidad de quien pretenda beneficiarse con el funcionamiento operativo del permiso y protagonista de la causación del mal menor. 4. La inminencia de la producción del mal mayor que se pretende evitar. (5)

Volviendo al fallo en cuestión, la falta de proporcionalidad no es "el punto clave" de la legítima defensa, tal como lo sostienen, sino que cada uno de los elementos son relevantes. Deben concurrir todos para su configuración. Es erróneo lo que plantean cuando consideran en relación a la legítima defensa o del estado de necesidad, el mal causado debe ser menor o igual al que se quiere evitar (...).

En la legítima defensa no se exige que exista esta ponderación de los bienes jurídicos en juego, como si lo requiere el estado de necesidad justificante.

Otra cuestión curiosa y errónea planteada por el tribunal es el desconocimiento absoluto del instituto de la tentativa regulado en el art. 42 del CP.

En el iter criminis, es decir, en el camino del delito, existen determinadas etapas que no son punibles, tales como la ideación, planeamiento y actos preparatorios. A partir de la ejecución de la 
conducta delictiva comienza a operar el aparato punitivo estatal. Se dice que un delito queda en grado de tentativa cuando el individuo comienza su ejecución pero no logra la consumación por circunstancias ajenas a su voluntad.

Así en el fallo que analizamos, el sujeto ingresa a un domicilio, independientemente de los fines. No es relevante porque el solo ingreso a un domicilio sin autorización implica una conducta delictual tipificada como violación de domicilio en el art. 150: Será reprimido con prisión de seis meses a dos años, si no resultare otro delito más severamente penado, el que entrare en morada o casa de negocio ajena, en sus dependencias o en el recinto habitado por otro, contra la voluntad expresa o presunta de quien tenga derecho de excluirlo.

La Dra. Zavala de González sostiene que lo que cuenta son los actos del agresor, no sus intenciones. Por eso, carece de toda relevancia que el ingreso se procurara con el objetivo de hurtar, no de matar o de herir. (6)

Pese a que sostuvo esta premisa, acertada a mi modo de individualizar estas cuestiones, luego rechaza su propia afirmación de manera contradictoria considerando que (E)I sujeto en cuestión ya había cometido delito de violación de domicilio (art. 150, Cód. Penal), y la circunstancia de que no portara armas -ignorada por el agredido- no descarta un ánimo eventual de ejercer "fuerza en las cosas" o "violencia física en las personas" si encuentra alguna resistencia o, al menos, si no se le entregan dinero u otros objetos de valor; según muestran con lamentable elocuencia las crónicas policiales cotidianas. Ello traslada a una tentativa de robo, y a posibles homicidios o lesiones con motivo o en ocasión de robo (arts. 164 y 165). (7)

Lo que resta preguntar es ¿importan o no los fines que tiene un individuo al ingresar a un domicilio sin autorización?

Claramente se impone la negativa. El individuo cometió el delito de violación de domicilio. No comparto lo que sostuvo el tribunal que consideró que el ingreso constituyó un "acto preparatorio de un delito de hurto que no tuvo principio de ejecución" porque no es posible advertir el aspecto doloso que el tipo penal de hurto requiere. La finalidad delictiva resulta irrelevante en el análisis del fallo. Lo único que debe establecer el juez civil es la procedencia o no de la demanda por daños y perjuicios. La finalidad del sujeto podría haber sido de lo más variada, así por ejemplo comer un fruto de un árbol del jardín, 
conducta que no configura un delito penal o hurtar ropa colgada en el patio de la casa o robar dinero de los ocupantes o matar por placer, etc. Las posibilidades son infinitas.

Los actos preparatorios no son punibles, con lo cual si en el mejor de los casos hubiera existido la tentativa del delito de hurto, la expresión correcta tendría que haber sido "que en el presente caso al existir principio de ejecución del delito de hurto y no lograr la consumación por ende queda en grado de tentativa".

En el ámbito penal, delimitar la tentativa y la consumación de los delitos generó y aun genera un arduo debate por diversos matices que no son objeto del presente trabajo.

\section{Conclusiones}

En el caso no se presenta una causa de justificación como la legítima defensa. Lo que es erróneo es el fundamento que le dan a la eximente de antijuridicidad.

La expresión "acto preparatorio de un delito de hurto" es absolutamente desacertada por los motivos expuestos.

Cabe realizar una segunda pregunta en este trabajo, ¿es posible el reclamo de daño moral al sujeto que con su accionar ilícito generó en el dueño del inmueble una reacción violenta que le produjo una paraplejia?

Si tomamos como punto de referencia el art. 1071 CC "(...) La ley no ampara el ejercicio abusivo de los derechos. Se considerará tal al que contraríe los fines que aquélla tuvo en mira al reconocerlos o al que exceda los límites impuestos por la buena fe, la moral y las buenas costumbres" y el art. 1.086 que establece que "Si el delito fuere por heridas u ofensas físicas, la indemnización consistirá en el pago de todos los gastos de curación y convalecencia del ofendido, y de todas las ganancias que éste dejó de hacer hasta el día de su completo restablecimiento." podríamos concluir que en el caso puesto como objeto de análisis, no sería procedente admitir el reclamo del daño moral, pero si los daños patrimoniales, que consisten en los gastos hospitalarios. El lucro cesante no fue considerado como rubro indemnizatorio en el caso de autos. 
Admitir un reclamo de daño moral, con un monto de indemnización tan elevado implica un ejercicio abusivo del derecho, máxime cuando el hecho que ocasionó la lesión en el actor tiene como origen su propio accionar delictivo.

(1) ORGAZ, Alfredo, Legítima defensa, LL, t. 147, p.923.

(2) LLAMBÍAS, Jorge Joaquín, Tratado de Derecho Civil. Obligaciones, t. III, $2^{\mathrm{a}}$ ed., Perrot, Buenos Aires, p. 632.

(3) Gran parte de la doctrina penal considera que para el funcionamiento de las causas de justificación se deben tener presentes tanto los elementos objetivos como los subjetivos. Así por ejemplo un sujeto puede creer que existe una agresión ilegítima (caso de robo con un arma de juguete) cuando en verdad no hay una puesta en peligro de ningún bien jurídico. Otra corriente considera que basta con la presencia de los elementos objetivos de una causa de justificación para configurar la eximente.

(4) Ver al respecto MELLACE, Mariela Esther, Los límites a la legítima defensa en la responsabilidad civil., en GHERSI, Carlos A.; dir., Daño a la Persona y al Patrimonio, Volumen I, Rosario, Nova Tesis, 2011, p. 449 y ss.

(5) RUSCONI, Maximiliano, Derecho Penal. Parte General, $2^{a}$ ed., Buenos Aires, Ad- Hoc, 2009, p. 417.

(6) ZAVALADE GONZÁLEZ, Matilde, Daños causados a un agresor ilegítimo, LL 05/12/2012, 6.

(7) ZAVALA DE GONZÁLEZ, Matilde, ob.cit. 